\title{
Dynamics and drivers of land use and land cover changes in Bangladesh
}

\author{
Xiaoming $\mathrm{Xu}^{1}$ (D) $\cdot$ Suravi Shrestha ${ }^{1} \cdot$ Hammad Gilani $^{1} \cdot$ Murali K. Gumma ${ }^{2} \cdot$ Baktiar N. Siddiqui $^{3} \cdot$ Atul K. Jain $^{1}$
}

Received: 6 May 2019 / Accepted: 19 April 2020 / Published online: 7 May 2020

(C) The Author(s) 2020

\begin{abstract}
Bangladesh has undergone dramatic land use and land cover changes (LULCC) in recent years, but no quantitative analysis of LULCC drivers at the national scale exists so far. Here, we quantified the drivers of major LULCC in combination with biophysical and socioeconomic observations at the sub-district level. We used Landsat satellite data to interpret LULCC from 2000 to 2010 and employed a Global Surface Water Dataset to account for the influences of water seasonality. The results suggest that major LULCC in Bangladesh occur between agricultural land and waterbodies and between forest and shrubland. Exclusion of seasonal waterbodies can improve the accuracy of our LULCC results and driver analysis. Although the gross gain and loss of agricultural land are large on the local scale, the net change (gross gain minus gross loss) at a country scale is almost negligible. Climate dynamics and extreme events and changes in urban and rural households were driving the changes from forest to shrubland in the southeast region. The conversion from agricultural land to standing waterbodies in the southwest region was mainly driven by urban household dynamics, population growth, distance to cities and major roads, and precipitation dynamics. This study, which is the first effort accounting for water seasonality and quantifying biophysical and socioeconomic drivers of LULCC at the national scale, provides a perspective on overall LULCC and underlying drivers over a decadal time scale and national spatial scale and can serve as a scientific basis for developing land policies in Bangladesh.
\end{abstract}

Keywords Satellite data $\cdot$ Socioeconomic data $\cdot$ Land use change $\cdot$ Drivers $\cdot$ Water seasonality $\cdot$ Deforestation $\cdot$ Agriculture Aquaculture

\section{Introduction}

Land use and land cover changes (LULCC) is the key topic in global change studies since they can alter regional and global

Communicated by Jasper van Vliet

Electronic supplementary material The online version of this article (https://doi.org/10.1007/s10113-020-01650-5) contains supplementary material, which is available to authorized users. climate through changing biophysical, biogeochemical, and biogeographical characteristics of the Earth system (Jain et al. 2013; Robinson et al. 2013; Xu et al. 2016). Understanding LULCC dynamics and drivers can help to
Xiaoming Xu

xuxm@illinois.edu

$\triangle \quad$ Atul K. Jain

jain1@illinois.edu

Suravi Shrestha

sshrest2@illinois.edu

Hammad Gilani

hgilani@illinois.edu

Murali K. Gumma

m.gumma@cgiar.org
Baktiar N. Siddiqui

baktiar1971@gmail.com

1 Department of Atmospheric Sciences, University of Illinois, Urbana, IL 61801, USA

2 International Crops Research Institute for the Semi-Arid Tropics (ICRISAT), Patancheru, Telangana, 502324, India

3 Chattogram North Forest Division, Bangladesh Forest Department, Banbhaban, Agargaon, Dhaka 1207, Bangladesh 
better understand the LULCC processes and mechanisms to develop models and land policies for a country. LULCC is driven by anthropogenic activities, such as socioeconomic development. It is also influenced by biophysical factors, such as climate, terrain, and soil quality (Dewan et al. 2012). Globally, about $60 \%$ of land changes are associated with direct human activities and the rest with indirect drivers, such as climate change during the period 1982-2016 (Song et al. 2018). Specifically, $27 \%$ of global forest loss can be attributed to commodity production over the period 2001 to 2015 (Curtis et al. 2018). At the regional scale of Southeast Asia, it is reported that forest loss is related to the cropland expansion (Zeng et al. 2018a, b). However, the quantitative analyses on the LULCC drivers at the national scale are still limited, especially in developing countries, which have experienced greater LULCC in recent years (Dewan and Yamaguchi 2009; Sloan and Sayer 2015).

Bangladesh has experienced LULCC over the years due to population and economy growth, infrastructure expansion (Islam and Hassan 2011), and climate change (Rahman and Manprasert 2006). The agricultural land in Bangladesh is threatened by soil salinity, productivity loss (especially in the coastal areas) (Hossain 2015), and climate events, such as floods (Amin et al. 2015), which may devastate vegetation and man-made facilities and therefore cause LULCC at the local scale. In addition, despite the efforts made by local government and international programs, forest areas continue to decrease (Chowdhury and Koike 2010; Hasan et al. 2017; Rasul et al. 2004; Reddy et al. 2016) and may disappear in the next 30-40 years or earlier (Chowdhury and Koike 2010). Extensive water resources (in the form of ponds, natural depressions, lakes, canals, rivers, estuaries, and coastal areas) have contributed to the aquaculture industry expansion in recent decades (Gias 2005; Shamsuzzaman et al. 2017). The aquaculture in Bangladesh can be broadly divided into two types, freshwater aquaculture (mainly comprised of pond fish farming) and coastal aquaculture (mainly shrimp farming) (Gias 2005). The area of fish ponds in Bangladesh has increased from $2,655 \mathrm{~km}^{2}$ in $2001-2002$ to $3,700 \mathrm{~km}^{2}$ in 2013-2014, while the area of coastal shrimp farms has nearly doubled from $1,414 \mathrm{~km}^{2}$ in 2001-2002 to $2,753 \mathrm{~km}^{2}$ in 20132014 (Fisheries Resources Survey System 2003, 2016) due to increased demand of shrimps in the international market (Inderbitzin et al. 2010). In addition, the conversion of traditional paddy culture land to shrimp culture ponds is a wellestablished practice in the southwest coastal area of Bangladesh (Ali 2006; Khan et al. 2015).

With these observed LULCC in Bangladesh, a number of studies have focused on understanding the dynamics and drivers of LULCC and their impacts (Ali 2006; Dewan and Yamaguchi 2009; Hossain 2015; Hossain et al. 2001; Islam et al. 2016; Reddy et al. 2016; Soil Resource Development Institute 2013; Yesmin et al. 2014). However, most of these local and regional-scale studies cannot be used to quantify the relations between LULCC and the driving factors for the entire country, which has 8 divisions, 64 districts (zila), and 484 sub-districts (upazila) with different socioeconomic conditions (one zila consists of approximately 8 upazilas, and the average size of an upazila is $\sim 300 \mathrm{~km}^{2}$ ). Thus, the objective of our study is to improve our understanding of the dynamics and drivers of LULCC at the national scale, which is of great importance for managing future challenges in LULCC. We especially address the following key questions regarding LULCC in Bangladesh: (1) What are the major LULC conversions between 2000 and 2010? (2) What are the major biophysical and socioeconomic drivers of these conversions?

To address these questions, we (1) quantify LULCC at national scale using a wall-to-wall analysis of $30 \mathrm{~m}$ resolution Landsat imageries at a decadal time interval (2000-2010), (2) compile the spatial biophysical drivers from global gridded datasets and socioeconomic drivers from national census data at sub-district level, (3) apply logistic regression to study the relationships between major LULCC and the drivers, and (4) evaluate and reinforce our findings on spatial drivers using the synthesis of case studies that incorporate field knowledge of the dynamics and drivers of LULCC in Bangladesh.

\section{Materials and methods}

The overall approach to study the dynamics and drivers of LULCC is broken down into six steps (Fig. 1). We describe these steps in detail in the following sections.

\section{Quantifying the land use and land cover change}

We use the USGS Landsat 5 Surface Reflectance Tier 1 cloudfree images at $30 \mathrm{~m}$ spatial resolution taken from Google Earth Engine (Masek et al. 2006). This dataset is produced from Landsat 5 TM L1TP data (level-1 precision and terrain corrected product) and is atmospherically corrected using LEDAPS (Schmidt et al. 2013). We use the scenes of winter months (October-February) to minimize the effects of cloud and seasonal variation. We use the images in adjacent years of 2000 and 2010 to ensure the image quality. Path/row and date information of the used scenes are shown in Table S1.

We apply a geographic object-based image analysis (GEOBIA) classification technique to extract the LULC information from Landsat satellite scenes using eCognition (Trimble Inc., Sunnyvale, CA, USA, 2016) (Gilani et al. 2015; Uddin et al. 2015). The GEOBIA method first identifies adjacent pixels in satellite images with similar spatial and spectral characteristics and partitions the images into distinct segments (Hay and Castilla 2008) and then classifies these segments into different LULC types. We classify Bangladesh into eight LULC types-agricultural land, 


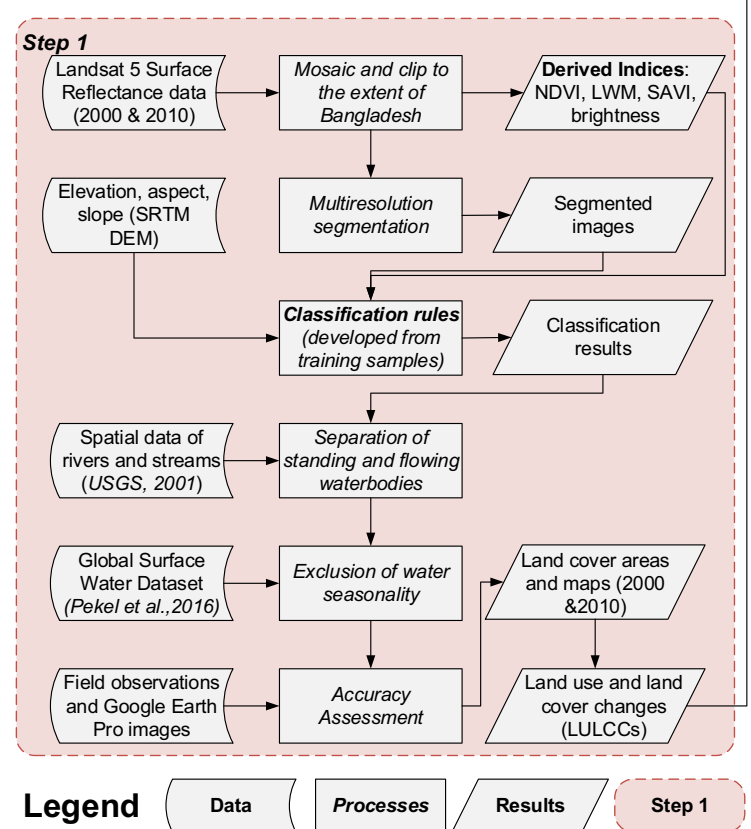

Fig. 1 Flowchart diagram of methodology. NDVI is short for normalized difference vegetation index; LWM represents land-water mask; SAVI means soil-adjusted vegetation index. Different shaped boxes represent

shrubland, bare land, forest, flowing waterbodies, standing waterbodies, settlement, and mangrove. Our study only focuses on the permanent LULCC. Therefore, we define the standing and flowing waterbodies as areas covered by water throughout the entire year (i.e., permanent water). A detailed description of the LULC classes can be found in Table S2. Our estimated agricultural land area does not subdivide the areas into croplands, plantation and grass/pasturelands, because of the lack of ground observed information.

We use a multi-resolution segmentation method in eCognition. We first identify the scale, shape, and compactness parameters appearing in this method from previous studies (Gilani et al. 2015; Uddin et al. 2015) and then tune and test these parameters to obtain a satisfied segmentation result. We use the following parameters for segmentation: scale, 25; shape, 0.1; and compactness, 0.5 . We use highresolution satellite information (such as QuickBird and IKONOS available within Google Earth Pro) to select reference segments (at least 10 for each LULC classes) as training datasets. Overall, $75 \%$ of training datasets are randomly selected for developing the classification rules, and the rest are used for validation (Uddin et al. 2015). The classification rules are developed by analyzing the spectral bands, the geometry of the segments, and the spatial contextual parameters. The detailed parameters include TM5 spectral bands, normalized difference vegetation index (NDVI), landwater mask (LWM), soil-adjusted vegetation index (SAVI), brightness, altitude, aspect, and slope (from SRTMGL1 v003

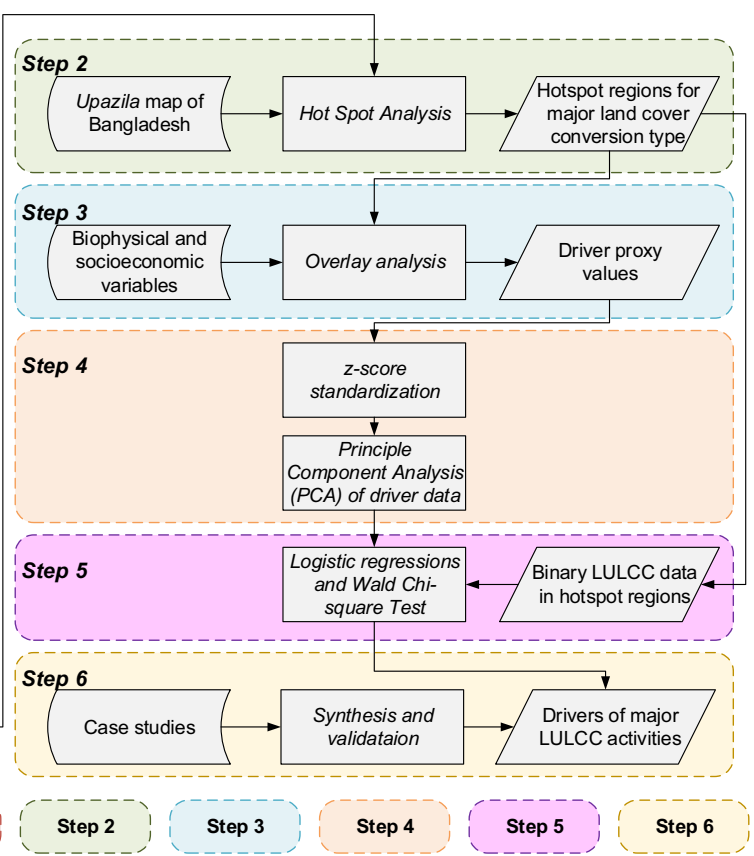

data, processes, and results. Six steps are shown in rounded rectangle with different colors

product on Google Earth Engine). The detailed calculation methods of these indices can be found in Gilani et al. (2015).

After the rule-based classification, we use a GIS layer of the rivers and streams (US Geological Survey 2001) to separate flowing and standing waterbodies. This separation only applies to waterbodies and has no effect on rice paddy, which has been classified as a part of agricultural land during the rule-based classification. The waterbodies, which are overlaid with (and close to) the rivers and streams, are classified as flowing waterbodies. Other waterbodies are classified as standing waterbodies. The separation of flowing and standing waterbodies helps to identify the dynamics of lands used for aquaculture, which is an important economic sector in Bangladesh. We consider the impacts from water seasonality by excluding seasonal waterbodies in this study using the Global Surface Water Dataset (Pekel et al. 2016) (see Supplementary Text S1 for detailed procedures and Fig. S1 for the water seasonality maps). Water seasonality discriminates between permanent and seasonal waterbodies, which are defined as waterbodies that are underwater throughout the year and less than 12 months of the year (Pekel et al. 2016). Inclusion of seasonal waterbodies may hinder the driver analysis of waterbody changes. For example, only permanent standing waterbodies can be used for aquaculture; lack of water seasonality information may affect the driver analysis. Therefore, our study focuses only on permanent LULCC. We use the confusion matrix method to assess the classification accuracy (Congalton 1991; Foody 2002) (Supplementary Text S2 and Tables S3 and S4). 


\section{Identifying the hotspot zones}

The inclusion of low-value regions may dilute the importance of key drivers (Xu et al. 2019). To exclude the regions with smaller areas of LULCC in our driver analysis, we use Hot Spot Analysis (Getis-Ord Gi*) tool in ArcMap 10.4 (ESRI Inc., Redlands CA, USA, 2016) to identify the aggregated areas of major LULCC. The $G i *$ statistic, which measures zscores of spatially clustered values to identify hotspot regions (Ord and Getis 1995), is performed within the context of neighboring features (upazilas in our case) inside a specified distance band. We use the fixed distance band, which means all neighboring features inside a fixed distance band (Euclidean distance that ensures every feature has at least one neighbor) are all incorporated with equal weight in the computations for the target upazila. Therefore, we do not specify any weight matrix file in this analysis. We consider upazilas with $z$-scores greater than 3 (99\% confidence level) as the hotspot regions.

\section{Proxy data of the biophysical and socioeconomic drivers}

\section{Biophysical proxy data}

Considering the significant impacts of climate change on LULCC in Bangladesh (Chowdhury and Ndiaye 2017), we include seasonal mean temperature and precipitation from 2000 to 2010 as proxy data of the biophysical drivers. We calculate the average values, increasing rate, and standard deviation for temperature and precipitation, for whole year, monsoon months (June-September), and postmonsoon months (October-November) to represent their inter-annual trends based on the CRU NCEP Reanalysis data (Jones and Harris 2014). The increasing rates of precipitation and temperature are calculated using the linear regressions over the years. We use elevation information from the SRTMGL1 v003 product to indicate the topographical features (Yang et al. 2011) and include annual mean values and standard deviation of soil moisture as driver proxies (Le Quéré et al. 2016). A detailed list of proxy data for biophysical drivers is provided in Table S5.

\section{Socioeconomic proxy data}

Our socioeconomic database includes 13 variables for 484 sub-districts (Table S5). We have collected tabular data for socioeconomic variables in two consecutive census years (2001 and 2011) from the Bangladesh Bureau of Statistics (BBS) (Bangladesh Bureau of Statistics 2001, 2012). For upazilas whose boundaries have changed over 2000-2010, we subdivide or merge the census data to derive the values for the original upazilas (Sloan 2015). We also include the
Euclidean distances to major cities and major highways and other major roads as two socioeconomic proxies based on the spatial data shown in Fig. S2.

\section{Addressing the multi-collinearity of driver proxy data}

We first calculate the matrix of correlation coefficients for the driver proxy data (Table S6 and S7) to identify a higher level of multi-collinearity among the proxy data for all changes. Then we use the principal component analysis (PCA) method to address the multi-collinearity prior to the logistic regression (Du et al. 2014), because the PCA method generates a set of orthogonal variables from original driver proxies while keeping all driver proxies, which helps us to better interpret the LULCC driver results. We include the components that have $\geq 85 \%$ cumulative proportions of variance in the logistic regression (Du et al. 2014). After modeling the relationship between major LULCC and components ("Modeling the drivers using logistic regression" section), we convert the regression coefficients of the PCs back to the original driver proxies (detailed procedures can be found in Supplementary Text S3).

\section{Modeling the drivers using logistic regression}

We use the LULCC data in the hotspot zones to generate the binary dependent variable ( 1 for LULCC activity occurred and 0 for no LULCC occurred) for the LULCC driver analysis (see Supplementary Text S3 for detailed explanation). We keep the original resolutions of the socioeconomic ( $300 \mathrm{~km}^{2}$ on national average) and biophysical proxy data $\left(0.5^{\circ} \times 0.5^{\circ}\right)$, because downscaling the proxy data to finer resolutions will change the mapping unit of the original data, which may induce the modifiable areal unit problem (MAUP) that causes bias for our logistic regression.

We analyze the drivers of two major LULCC, forest to shrubland and agriculture to standing waterbodies. These activities have relatively large areas and are affected by both biophysical and socioeconomic factors. The 10-year interval conversion data from forest to shrubland also include the changes caused by shifting cultivation (locally referred to as Jhum). This practice involves clearing of forests and shrubs by slashing and burning the crop cultivation, followed by a fallow period (Hossain 2011). The cycling period of shifting cultivation has reduced from $15-25$ years in the 1960 s to $2-$ 4 years in 1990s (Hossain 2011). A short fallow time does not allow the natural regeneration of forest; when next cultivation starts, the fallow lands are mostly shrubland. Thapa and Rasul (2006) also report an increase of the shrubland area due to the short fallow time. Thus, we treat the change from forest to shrubland over the 10-year interval as "permanent" deforestation activity. We have not analyzed the drivers of the changes between flowing waterbodies, barren land, and other LULC 
types, because these changes are mainly due to migration of river channel (Bristow 1987) rather than our driver proxies. We have also estimated the drivers of other three important LULCC activities: shrubland to agricultural land, shrubland to forest, and agricultural land to settlement. We use logistic regression to model the drivers of the LULCC and Wald Chi-Square test to evaluate the statistical significance of the logistic regression results. Detailed data processing and model algorithms can be found in Supplementary Text S3.

\section{Synthesis of case studies}

We have synthesized existing case studies on the drivers of LULCC in Bangladesh to (1) get a better understanding of the LULCC dynamics, (2) identify potential drivers of LULCC, (3) identify the gaps in the existing studies (e.g., lack of understanding of driving factors at a sub-district level), and (4) collect evidences to complement and evaluate the results of our study (Table S8).

\section{Results}

\section{Land use and land cover change}

We have conducted accuracy assessments for 2 years of LULC maps separately. The overall accuracy rates of the LULC maps in 2000 and 2010 are $89.70 \%$ and $96.14 \%$, while the Kappa indices are 0.92 and 0.92 , respectively (Tables S3 and S4). These results indicate the high accuracy of the classification results. The dominant LULC types in Bangladesh are agricultural land, forest, and waterbodies (flowing and standing) in both 2000 and 2010 (Table 1 and Fig. S3). The spatial patterns of these LULCs are similar in both years. Agricultural land is widely distributed in both years. Most forests are located in the eastern part of the Chittagong
Division (Fig. 2). Flowing waterbodies are mainly consisted of Padma (Ganges), Jamuna (Brahmaputra), and Meghna Rivers, while the standing waterbodies are mainly ponds in the Khulna Division, which is in the southwest of the country.

There are significant exchanges between agricultural land and other land cover classes (e.g., shrubland, barren land, flowing and standing waterbodies, and forest) as shown in Fig. 3 and Table S9. The roughly similar areas of gross gain and loss in agricultural land cause the negligible net change (Fig. 3). Similarly, mangrove also has a small net change. Areas increased from 2000 to 2010 for shrubland by $21.76 \%$, barren land by $41.06 \%$, settlement by $32.52 \%$, and standing waterbodies by $8.63 \%$ (Table 1 ) and decreased for forest by $8.90 \%$, flowing waterbodies by $2.88 \%$. The forest is mainly replaced by shrubland, which has increased by $694 \mathrm{~km}^{2}$. The decreasing rate of the forest is the greatest among all LULC types (Table 1), indicating intensive deforestation activities. The net increased rate of barren land of $40.90 \%$ is the highest among all LULC types. The sources of increased barren land are mainly from agricultural land and flowing waterbodies (Fig. 3 and Table S9). The standing waterbody area has increased by $8.58 \%$, because a large area of agricultural land is converted to standing waterbodies.

Our hotspot regional analyses show that the conversions from agriculture to standing waterbodies have mainly occurred in the southwest region of the country (Khulna Division) and forest to shrubland conversion is concentrated mainly in Chittagong Division, which is in the southeast region of the country (Fig. 2). The hotspot regions for the changes from shrubland to agricultural land and forest are overlaid in Chittagong Division, while the changes from agricultural land to the settlement have mainly occurred in the northern part of Dhaka City and eastern Chittagong Division (Fig. S4). Comparison of our classification results with other published studies (Hasan et al. 2017; Reddy et al. 2016; Soil Resource Development Institute 2013) at the national scale show a
Table 1 Land use and land cover areas in 2000 and 2010

\begin{tabular}{|c|c|c|c|c|c|}
\hline & \multicolumn{2}{|l|}{2000} & \multicolumn{2}{|l|}{2010} & \multirow{2}{*}{$\begin{array}{l}\text { Relative change } \\
\text { (\%) 2010-2000 }\end{array}$} \\
\hline & Area $\left(\mathrm{km}^{2}\right)$ & Percentage $(\%)$ & Area $\left(\mathrm{km}^{2}\right)$ & Percentage $(\%)$ & \\
\hline Agricultural land ${ }^{1}$ & 120,481 & 80.91 & 120,634 & 81.02 & 0.13 \\
\hline Shrub land & 3189 & 2.14 & 3883 & 2.61 & 21.77 \\
\hline Barren land & 453 & 0.30 & 639 & 0.43 & 40.90 \\
\hline Flowing waterbody & 6434 & 4.32 & 6249 & 4.20 & -2.87 \\
\hline Forest & 12,054 & 8.10 & 10,981 & 7.37 & -8.90 \\
\hline Settlement & 615 & 0.41 & 815 & 0.55 & 32.55 \\
\hline Mangrove & 4899 & 3.29 & 4857 & 3.26 & -0.85 \\
\hline Standing waterbody & 776 & 0.52 & 843 & 0.57 & 8.58 \\
\hline Sum & 148,901 & 100.00 & 148,901 & 100.00 & \\
\hline
\end{tabular}

${ }^{1}$ Including croplands, plantation, and grass/pasturelands 
Fig. 2 Spatial pattern of land use and land cover changes (LULCC) in Bangladesh between 2000 and 2010. The base map is the land use and land cover map of 2000. The color and size of circles represent LULCC types and areas. Bold lines in different colors indicate the hotspot regions of the two LULCC types

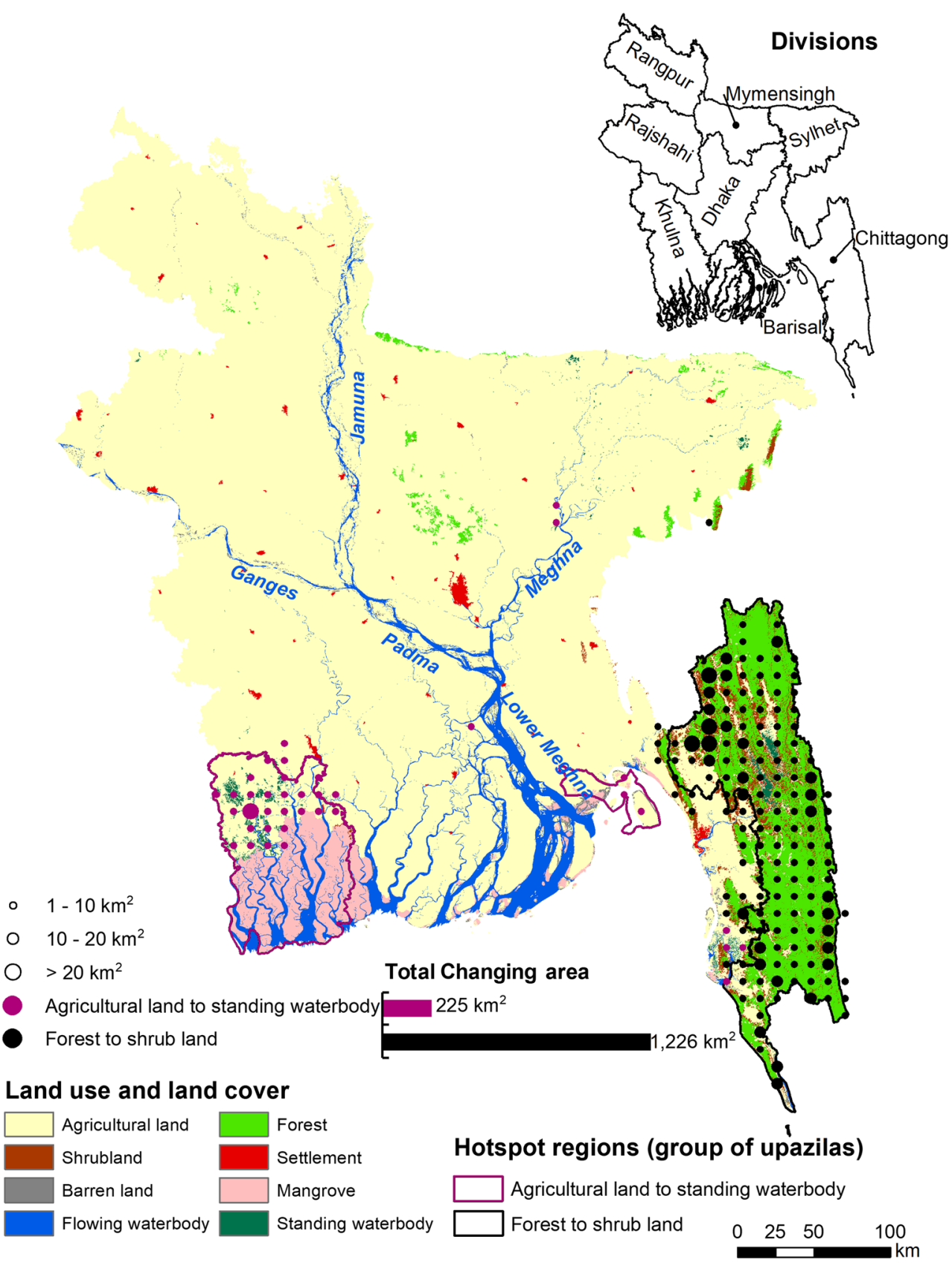

greater agricultural land area and smaller forest and settlement area based on our study (Table S10). The differences in satellite images, classification methods, auxiliary data, and LULC class definitions have caused divergences in the classification results (see detailed discussion in Supplementary Text S4). We have also evaluated our land cover classification result with two global datasets: (1) European Space Agency Climate Change Initiative (ESA CCI) Land Cover data (Santoro et al. 2017) with $300 \mathrm{~m}$ spatial resolution at yearly time step from 1992 to 2015 and (2) the GlobeLand30 data (Chen et al. 2015) with $30 \mathrm{~m}$ resolution available at year 2000 and 2010 (Table S11). We have followed the metrics developed by
Sbafizadeh-Moghadam et al. (2019) to compare the LULCC results (Table S12 and S13). We find a similar estimation of LULCC between our data and the ESA CCI data, but greatly different from the GlobeLand30 data. We discuss the comparison results in detail in Supplementary Text S5.

\section{Major drivers}

We use the standardized coefficients of driver proxies from the logistic regressions to indicate the impacts of different drivers (Fig. 4). The standardized coefficients refer to how many standard deviations the LULCC area will change per standard 
Fig. 3 Gross gains, gross losses, and net changes in land use and land cover at a national scale $\left(\mathrm{km}^{2}\right)$ over the period 2000-2010. The areas of the gains and losses from one land use/cover type (the $y$-axis) to the other land use/cover types between 2000 and 2010 are showed in different colors (except black). Black bars demonstrate the net changes (gross gainsgross losses) of different land use/ cover types (the $y$-axis)

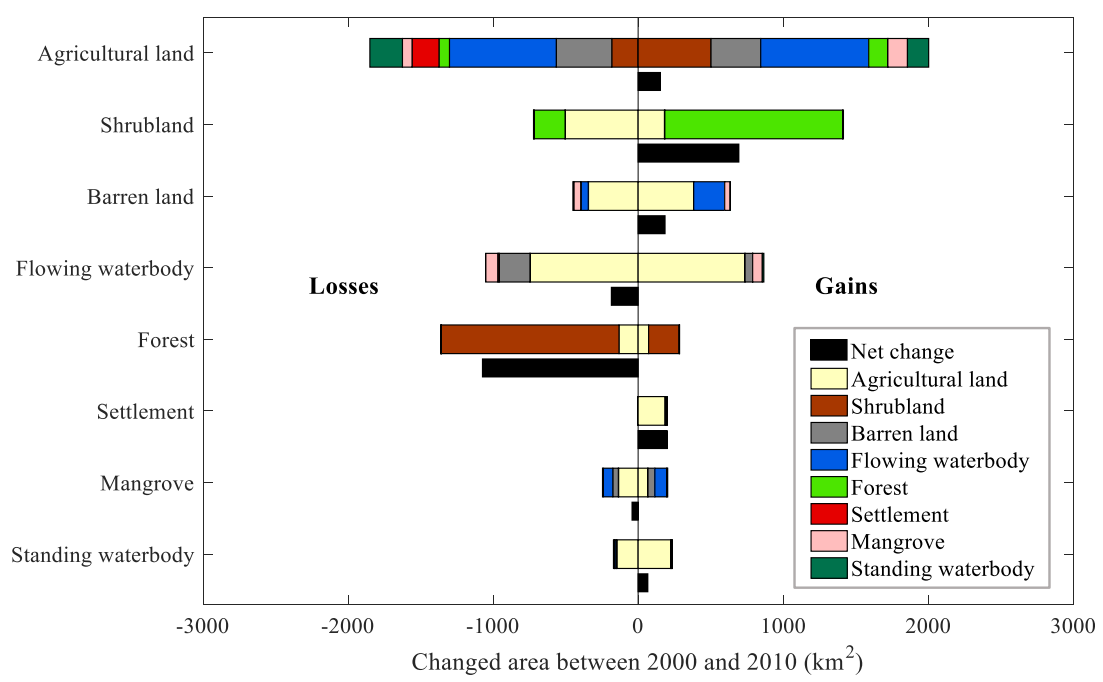

deviation increase in the driver proxy data. We have standardized the driver proxy data; therefore, the standardized coefficients allow comparisons of the relative impacts of driver proxies measured on different scales. The relative importance is determined by the absolute mean estimates across coefficients. A positive relationship means that higher values of a driver proxy correspond to greater LULCC areas, whereas a negative relationship refers to higher values of a driver proxy which correspond to smaller LULCC areas. In this section, we only describe the results of the driver analysis. The interpretation and discussion of these results are described in the "Interpretation and explanation of the drivers" section.

\section{Conversion from forest to shrubland}

There are seven major biophysical drivers for the conversion from forest to shrubland (Fig. $4 \mathrm{a}$ and Table S14). Increasing rate and standard deviation of temperature are the two most important drivers, and both have positive impacts (the positive relationship between drivers and LULCC) (Fig. 4a and Table S14). The increasing rate of temperature in monsoon months also has a positive impact on this change. In contrast, four precipitationrelated drivers, mean and standard deviation of precipitation both annually and in monsoon months, are negatively correlated to the changes (the negative relationship between drivers and LULCC). Socioeconomic drivers, including increasing rates of rural and urban household sizes and rural household numbers, are negatively correlated to this change.

\section{Conversion from agricultural land to standing waterbodies}

There are eight socioeconomic drivers and two biophysical drivers (Fig. 4b and Table S15) out of the ten most important drivers for the conversion from agricultural land to standing waterbodies. Population, urban and rural household numbers, and increasing rate of rural household size have negative impacts. The increasing rate of urban household size is positively associated with this change. Meanwhile, the distance to major cities and the connection ratio of electricity (percentage of total households that have access to electricity) are negatively associated with the change, but the distance to major highways and other major roads is positively correlated to the change. The biophysical drivers, distance to rivers, and increasing rate of precipitation in monsoon months all have negative impacts on the changes from agricultural land to standing waterbodies.

\section{Discussion}

\section{Interpretation and explanation of the drivers}

\section{Conversion from forest to shrubland}

Our results show that the forest proportion of Bangladesh in 2010 is $7.37 \%$, which is relatively small compared with other SSEA countries (Xu et al. 2019). Forest and its changes (specifically to shrubland) are mainly located in the Chittagong Division in southeast Bangladesh, which have also been reported in many other studies (Chowdhury and Koike 2010; Hasan et al. 2017; Rasul et al. 2004; Reddy et al. 2016). Biophysical drivers, mainly temperature and precipitation dynamics (Fig. 4a), greatly controlled this change. Increasing but unstable temperatures (higher values of increasing rate and standard deviation of temperature), especially in monsoon months, as well as lower and relatively stable precipitation conditions (lower values of mean precipitation and increasing rate of precipitation in monsoon months) facilitate forest loss (Fig. 4a). This type of condition might indicate extreme climate events, such as droughts, which may result in forest loss (Chowdhury and Ndiaye 2017). Meanwhile, lower and stable precipitation conditions may decrease forest 
Fig. 4 Ten most prominent drivers for the land use and land cover changes of a forest to shrub land and $\mathbf{b}$ agricultural land to standing waterbody from 2000 to 2010. Blue dots show the standardized coefficients, error bars show the $95 \%$ confidence interval. Standardized coefficients demonstrate the relative importance of each driver

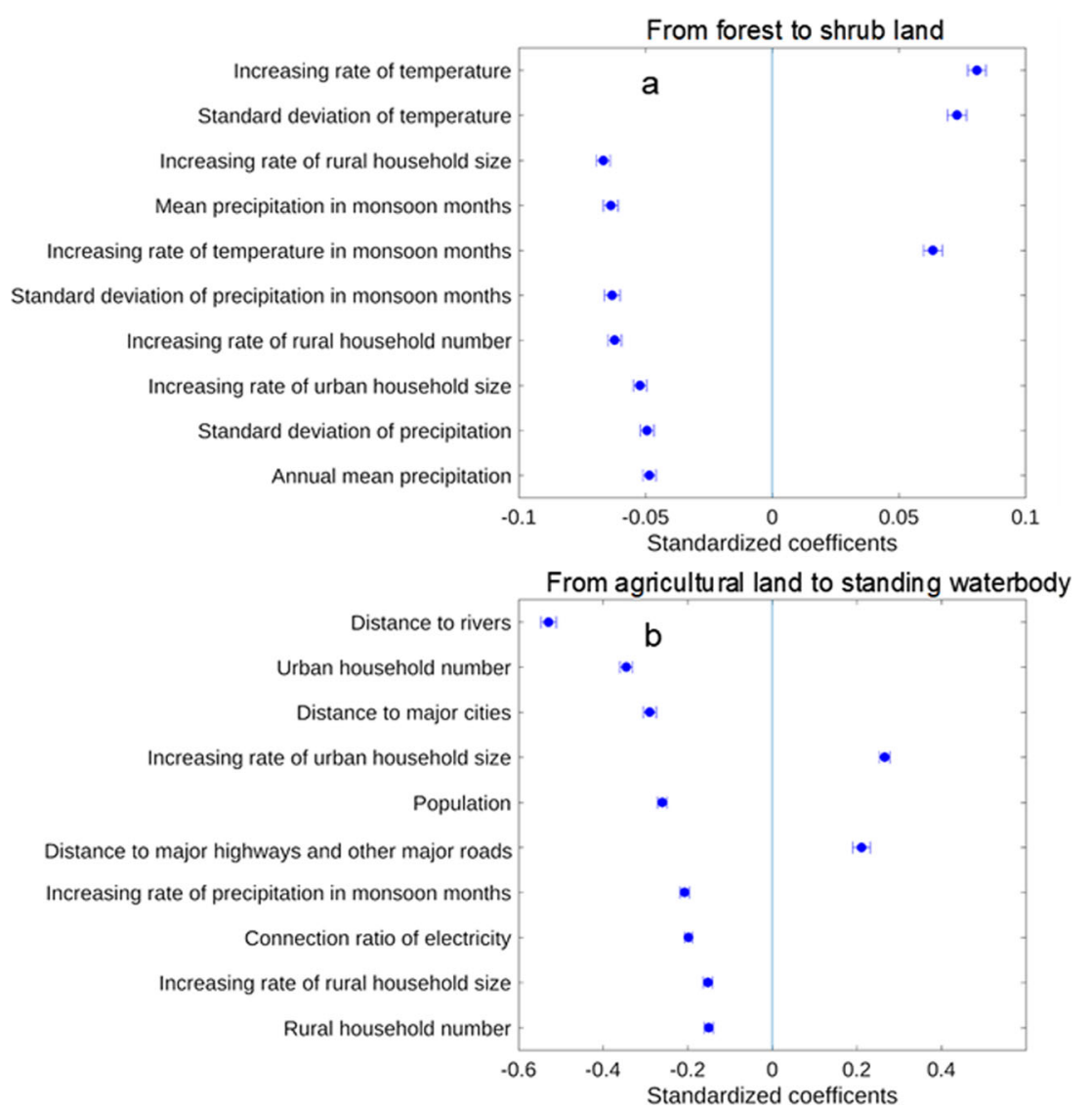

productivity (Rahman et al. 2015) and may lead the forest degradation.

Biswas and Choudhury (2007) suggest that socioeconomic factors, such as development of infrastructure and industry, caused deforestation in Bangladesh. However, based on our results we see that the dynamics in the urban and rural household are more important for this type of change. The negative relationships (Fig. 4b) illustrate that the conversion from forest to shrubland, which mainly occurred in regions with slower increasing rates of household size and number. Based on our study, such regions consist mainly of rural regions in the Chittagong Division where the majority of forests are concentrated (Fig. 2). In such areas, local people earn their livelihood by using resources and fuels from forests.

\section{Conversion from agricultural land to standing waterbodies}

The results of this study and synthesis analysis demonstrate that the aquaculture industry played an important role in driving the changes in standing waterbodies, which mainly include open waterbodies, such as haors and beels (natural depressions), and closed waterbodies, like baors (oxbow lakes) and ponds. The low-lying areas (haors), (e.g., northeast Sylhet and Mymensingh Divisions) are inundated in rainy seasons. When the dry season comes, water in haors recedes, leaving only more depressed lands under water, called beels (Banglapedia 2015). Our analysis suggests that the standing waterbodies in the northeast region are mainly seasonal water due to flooding during monsoon seasons. We used the Global Surface Water Dataset (Pekel et al. 2016) to exclude the seasonal standing waterbodies. As a result, the permanent standing waterbodies are mainly observed in a very limited area, particularly in Khulna Division in the southwest of the country (Fig. 2), in forms of baors and ponds, which are mainly used for aquaculture (Islam 2010). The most identifiable limitation of the global surface water data is the geographic and temporal discontinuities of the Landsat archive data (Pekel et al. 2016). There are some regions or periods lacking satellite observations, which may affect the discrimination of the seasonal and permanent water (Fig. S1). However, our analysis only accounts for permanent water. Therefore, the effect of missing data on our analysis results is minimum, because the regions or periods with no observations have been treated as seasonal water as well. All permanent water according to the global surface water data has continuous Landsat observations across the whole year.

The development of aquaculture is happening at the cost of agricultural land. This phenomenon is also observed by other satellite studies such as Abdullah et al. (2019). Our driver analysis indicates that the changes from agricultural land to standing waterbodies occur mainly in less populous rural regions with smaller household size, which are close to major 
cities. Compared with urban areas, these regions have relatively less access to infrastructures, such as electricity and major highways and roads (note that these regions still have enough infrastructure accesses than remote rural areas that enable preservation and transportation of aquaculture products). These regions are the most suitable areas for aquaculture development. On one hand, in urban regions, there are limited lands for aquaculture development and land expenses are higher. On the other hand, in remote rural areas far away from major cities, the preservation and transportation costs of aquaculture products are higher. In these less populous rural regions close to major cities, the relatively lower land expenses and preservation and transportation costs increase the economic profitability of aquaculture. This will lead more local families to convert their agricultural lands to standing waterbodies (Ahmed and Diana 2015; Ali 2006; Islam and Tabeta 2016). The regions close to major cities have higher domestic demands for aquaculture products. Meanwhile, the international demands for aquaculture products also significantly increased in past few years: the shrimp export (particularly to the USA and European Union) became the second largest export industry in Bangladesh in recent years (Ahmed and Diana 2015), and its value increased from 240 million US dollars in 2000-2001 to 459 million in 2015-2016 (Fisheries Resources Survey System 2016). Both domestic and international demands have incentivized farmers to change their agricultural land to standing waterbodies for aquaculture products.

Water availability directly affects aquaculture. The regions close to rivers (smaller value of distance to rivers) have more available water, which can facilitate the aquaculture ponds development. Both of our LULCC analyses (Fig. 2) and case studies (Abdullah et al. 2019; Islam 2010) suggest that shrimp farming is mainly located in the water-rich coastal regions of southwest Bangladesh. Changes in climate, such as the increasing rate of precipitation in monsoon months in our results, have negative impacts on agricultural production in the southwest of the country (Amin et al. 2015; Huq et al. 2015), particularly the rice cultivation (Ali 2006). Literature research suggests that farmers might opt for aquaculture to avoid possible risks to agricultural production due to climate change, because Bangladesh has suitable agro-climatic conditions, adequate water resources, and cheap labor force (Paul and Vogl 2011) and the profit of aquaculture is higher than cultivation (e.g., shrimp farming is about 12 times more profitable than rice cultivation in Bangladesh (Ali 2006)).

We have also studied the drivers of the changes from shrubland to agricultural land, shrubland to forest, and agricultural land to settlement. The changes from shrubland to agricultural land are mainly driven by biophysical factors such as increasing rate of precipitation and mean soil moisture. Socioeconomic drivers, such as increasing rate of rural household size and increasing rate of population, are dominant in driving the change from shrubland to forest. For the changes from agricultural land to settlement, both socioeconomic (e.g., distance to major highways and other major roads and urban household number) and biophysical drivers (e.g., distance to rivers and elevation) are important (Fig. S5). We have discussed the drivers of these three LULCC activities in detail in Supplementary Text S6.

\section{Limitation and caveats}

While our analysis of spatial drivers of LULCC for Bangladesh is important and our analysis results are corroborated with other studies, there are some limitations related to the data and methods used. First, our analysis for the dynamics of LULCC captures only the decadal changes and can mask within-decade variations including intermediary land uses. However, wall-to-wall analysis of Landsat scenes at much finer temporal resolution is laborious and beyond the scope of this study. Second, our Landsat analysis detects changes in land type only when the magnitude of modification is large enough to cause a shift from one land cover category to another (e.g., forest to shrubland). However, in reality, forest loss and regrowth are gradual and cause subtle modifications to land cover. Nevertheless, our analysis bias is likely to be minimal because our statistical estimation weighs each observation (at grid cell) by the magnitude of land change; thus, small changes have less influence in our model analysis. Third, quality of the socioeconomic data in some regions may be poor due to misreporting, human errors in computerization, quality of village/town boundaries, or unavailability of data due to separation and union of different upazilas boundaries. Yet this is the most consistent and detailed data we can access. Finally, our analysis does not extend beyond 2010 due to lack of socioeconomic data. However, we will extend our land cover conversion estimates and its driver as soon as the data are available.

\section{Conclusions}

Through a comprehensive methodology, this study successfully reveals the dominant biophysical and socioeconomic drivers of major LULCC activities in Bangladesh. Climate dynamics and extremes are critical to the conversion from forest to shrubland, while population and accessibility to infrastructure are controlling factors of the conversion from agricultural land to standing waterbodies. This study is unique, because it advances a general understanding of the dynamics and drivers of LULCC at the national scale of Bangladesh, which will guide effective national-level planning and policymaking. Particularly, we have accounted for the impacts of water seasonality on LULCC analysis; such effort has not been reported in previous studies. Our study adds an additional quantitative dimension by providing the explanation of drivers of LULCC. In addition, the synthesis of case studies provides a more generalized understanding of the drivers of LULCC and reinforced the findings of our spatial 
determinants of LULCC in Bangladesh over the time period of 2000-2010.

Acknowledgment We thank Jean-François Pekel for his help with the Global Surface Water Dataset.

Funding information This work is supported by the U.S. Department of Energy (No. DE-SC0016323).

Data availability Our satellite LULC data for Bangladesh for years 2000 and 2010 can be downloaded for free from the ISAM website (http:// climate.atmos.uiuc.edu/Bangladesh/). We are sharing the data at $30 \mathrm{~m}$ spatial resolution. Our geospatial sub-district level socioeconomic database (covering 2001 and 2011) is also available at the same website.

Open Access This article is licensed under a Creative Commons Attribution 4.0 International License, which permits use, sharing, adaptation, distribution and reproduction in any medium or format, as long as you give appropriate credit to the original author(s) and the source, provide a link to the Creative Commons licence, and indicate if changes were made. The images or other third party material in this article are included in the article's Creative Commons licence, unless indicated otherwise in a credit line to the material. If material is not included in the article's Creative Commons licence and your intended use is not permitted by statutory regulation or exceeds the permitted use, you will need to obtain permission directly from the copyright holder. To view a copy of this licence, visit http://creativecommons.org/licenses/by/4.0/.

\section{References}

Abdullah AM, Masrur A, Adnan MSG, Al Baky MA, Hassan QK, Dewan A (2019) Spatio-temporal patterns of land use/land cover change in the heterogeneous coastal region of Bangladesh between 1990 and 2017. Remote Sens (Basel) 11. https://doi.org/10.3390/rs11070790

Ahmed N, Diana JS (2015) Coastal to inland: expansion of prawn farming for adaptation to climate change in Bangladesh. Aquac Rep 2: 67-76. https://doi.org/10.1016/j.aqrep.2015.08.001

Ali AMS (2006) Rice to shrimp: land use land cover changes and soil degradation in southwestern Bangladesh. Land Use Policy 23:421435. https://doi.org/10.1016/j.landusepol.2005.02.001

Amin MR, Zhang JB, Yang MM (2015) Effects of climate change on the yield and cropping area of major food crops: a case of Bangladesh. Sustainability-Basel 7:898-915. https://doi.org/10.3390/su7010898

Bangladesh Bureau of Statistics (2001) Population and housing census 2001 Bangladesh Bureau of Statistics (2012) Population and housing census 2011

Banglapedia (2015) Fisheries of Bangladesh. http://en.banglapedia.org/ index.php?title=Fisheries. Accessed Sep. 12017

Biswas SR, Choudhury JK (2007) Forests and forest management practices in Bangladesh: the question of sustainability. Int For Rev 9: 627-640. https://doi.org/10.1505/ifor.9.2.627

Bristow CS (1987) Brahmaputra River: channel migration and deposition. https://doi.org/10.2110/pec.87.39.0063

Chen J, Chen J, Liao A, Cao X, Chen L, Chen X, He C, Han G, Peng S, $\mathrm{Lu}$ M, Zhang W (2015) Global land cover mapping at $30 \mathrm{~m}$ resolution: a POK-based operational approach. ISPRS J Photogramm 103: 7-27. https://doi.org/10.1016/j.isprsjprs.2014.09.002

Chowdhury MSH, Koike M (2010) An overview on the protected area system for forest conservation in Bangladesh. J For Res 21:111-118. https://doi.org/10.1007/s11676-010-0019-x

Chowdhury R, Ndiaye O (2017) Climate change and variability impacts on the forests of Bangladesh - a diagnostic discussion based on
CMIP5 GCMs and ENSO. Int J Climatol 37:4768-4782. https:// doi.org/10.1002/joc.5120

Congalton RG (1991) A review of assessing the accuracy of classifications of remotely sensed data. Remote Sens Environ 37:35-46. https://doi.org/10.1016/0034-4257(91)90048-B

Curtis PG, Slay CM, Harris NL, Tyukavina A, Hansen MC (2018) Classifying drivers of global forest loss. Science 361:1108-1111. https://doi.org/10.1126/science.aau3445

Dewan AM, Yamaguchi Y (2009) Land use and land cover change in Greater Dhaka, Bangladesh: using remote sensing to promote sustainable urbanization. Appl Geogr 29:390-401. https://doi.org/10. 1016/j.apgeog.2008.12.005

Dewan AM, Yamaguchi Y, Rahman MZ (2012) Dynamics of land use/ cover changes and the analysis of landscape fragmentation in Dhaka Metropolitan, Bangladesh. GeoJournal 77:315-330. https://doi.org/ 10.1007/s10708-010-9399-x

Du X, Jin X, Yang X, Yang X, Zhou Y (2014) Spatial pattern of land use change and its driving force in Jiangsu Province. Int J Environ Res Public Health 11:3215-3232. https://doi.org/10.3390/ ijerph110303215

Fisheries Resources Survey System (2003) Fisherires statistical report of Bangladesh 2001-2002 vol 19. Fisheries Resources Survey System, Department of Fisheries, Bangladesh

Fisheries Resources Survey System (2016) Fisherires statistical report of Bangladesh 2014-2015 vol 32. Fisheries Resources Survey System, Department of Fisheries, Bangladesh

Foody GM (2002) Status of land cover classification accuracy assessment. Remote Sens Environ 80:185-201. https://doi.org/10.1016/ S0034-4257(01)00295-4

Gias UA (2005) National aquaculture sector overview Bangladesh. National aquaculture sector overview fact sheets. http://www.fao. org/fishery/countrysector/naso bangladesh/en. Accessed Dec. 12017

Gilani H, Shrestha HL, Murthy MS, Phuntso P, Pradhan S, Bajracharya B, Shrestha B (2015) Decadal land cover change dynamics in Bhutan. J Environ Manag 148:91-100. https://doi.org/10.1016/j. jenvman.2014.02.014

Hasan SS, Deng XZ, Li ZH, Chen DD (2017) Projections of future land use in Bangladesh under the background of baseline, ecological protection and economic development. Sustainability (Basel) 9 . https://doi.org/10.3390/su9040505

Hay GJ, Castilla G (2008) Geographic object-based image analysis (GEOBIA): a new name for a new discipline. In: Object-based image analysis. Springer, Berlin, pp 75-89. https://doi.org/10.1007/ 978-3-540-77058-9 4

Hossain M (2011) An overview on shifting cultivation with reference to Bangladesh. Sci Res Essays 6:6509-6514. https://doi.org/10.5897/ SRE11.1282

Hossain M (2015) Declining productivity of agricultural land in Bangladesh. J Agroecol Nat Resour Manag 2:25-30

Hossain M, Lin CK, Hussain MZ (2001) Goodbye Chakaria Sunderban: the oldest mangrove forest. Soc Wetl Sci Bull 18:19-22. https://doi. org/10.1672/0732-9393(2001)018[0019:GCSTOM]2.0.CO;2

Huq N, Huge J, Boon E, Gain AK (2015) Climate change impacts in agricultural communities in rural areas of coastal Bangladesh: a tale of many stories. Sustainability (Basel) 7:8437-8460. https://doi.org/ 10.3390/su7078437

Inderbitzin P, Bostock RM, Trouillas FP, Michailides TJ (2010) A six locus phylogeny reveals high species diversity in Botryosphaeriaceae from California almond. Mycologia 102: 1350-1368. https://doi.org/10.3852/10-006

Islam SN (2010) Threatened wetlands and ecologically sensitive ecosystems management in Bangladesh. Front Earth Sci in China 4:438 448. https://doi.org/10.1007/s11707-010-0127-0

Islam MR, Hassan MZ (2011) Land use changing pattern and challenges for agricultural land: a study on Rajshahi District. J Life Earth Sci 6: 69-74. https://doi.org/10.3329/jles.v6i0.9724 
Islam MR, Tabeta S (2016) Impacts of shrimp farming on local environments and livelihoods in Bangladesh. Int J Environ Sci 1:48-51

Islam MR, Miah MG, Inoue Y (2016) Analysis of land use and land cover changes in the coastal area of Bangladesh using Landsat imagery. Land Degrad Dev 27:899-909. https://doi.org/10.1002/ldr.2339

Jain AK, Meiyappan P, Richardson T (2013) Carbon emissions from land-use change: model estimates using three different data sets. In: Brown DG, Robinson DT, French NHF, Reed BC (eds) Land use and the carbon cycle: advances in integrated science, management, and policy. Cambridge University Press, Cambridge, p 241. https://doi.org/10.1017/CBO9780511894824.013

Jones P, Harris I (2014) Climatic Research Unit (CRU) Time-Series (TS) Version 3.22 of High Resolution Gridded Data of Month-by-month Variation in Climate (Jan. 1901-Dec. 2013). University of East Anglia Climatic Research Unit. NCAS British Atmospheric Data Centre, Oxford https://doi.org/10.1017/CBO9781107415324.004

Khan MMH, Bryceson I, Kolivras KN, Faruque F, Rahman MM, Haque U (2015) Natural disasters and land-use/land-cover change in the southwest coastal areas of Bangladesh. Reg Environ Chang 15:241250. https://doi.org/10.1007/s10113-014-0642-8

Le Quéré C, Andrew RM, Canadell JG, Sitch S, Korsbakken JI, Peters GP, Manning AC, Boden TA, Tans PP, Houghton RA, Keeling RF, Alin S, Andrews OD, Anthoni P, Barbero L, Bopp L, Chevallier F, Chini LP, Ciais P, Currie K, Delire C, Doney SC, Friedlingstein P, Gkritzalis T, Harris I, Hauck J, Haverd V, Hoppema M, Klein Goldewijk K, Jain AK, Kato E, Körtzinger A, Landschützer P, Lefèvre N, Lenton A, Lienert S, Lombardozzi D, Melton JR, Metzl N, Millero F, Monteiro PMS, Munro DR, Nabel JEMS, Nakaoka S-I, Brien K, Olsen A, Omar AM, Ono T, Pierrot D, Poulter B, Rödenbeck C, Salisbury J, Schuster U, Schwinger J, Séférian R, Skjelvan I, Stocker BD, Sutton AJ, Takahashi T, Tian H, Tilbrook B, van der Laan-Luijkx IT, van der Werf GR, Viovy N, Walker AP, Wiltshire AJ, Zaehle S (2016) Global carbon budget 2016. Earth Syst Sci Data 8:605-649. https://doi.org/10.5194/essd-8-605-2016

Masek JG, Vermote EF, Saleous NE, Wolfe R, Hall FG, Huemmrich KF, Gao F, Kutler J, Lim TK (2006) A Landsat surface reflectance dataset for North America, 1990-2000. IEEE Geosci Remote Sens Lett 3:68-72. https://doi.org/10.1109/Lgrs.2005.857030

Ord JK, Getis A (1995) Local spatial autocorrelation statistics - distributional issues and an application. Geogr Anal 27:286-306. https:// doi.org/10.1111/j.1538-4632.1995.tb00912.x

Paul BG, Vogl CR (2011) Impacts of shrimp farming in Bangladesh: challenges and alternatives. Ocean Coast Manag 54:201-211. https://doi.org/10.1016/j.ocecoaman.2010.12.001

Pekel JF, Cottam A, Gorelick N, Belward AS (2016) High-resolution mapping of global surface water and its long-term changes. Nature 540:418-422. https://doi.org/10.1038/nature20584

Rahman M, Manprasert S (2006) Landlessness and its impact on economic development: a case study on Bangladesh. J Soc Sci 2:54-60. https://doi.org/10.3844/jssp.2006.54.60

Rahman MS, Akter S, Al-Amin M (2015) Forest and agro-ecosystem productivity in Bangladesh: a climate vegetation productivity approach. For Sci Technol 11:126-132. https://doi.org/10.1080/ 21580103.2014.957358

Rasul G, Thapa GB, Zoebisch MA (2004) Determinants of land-use changes in the Chittagong Hill tracts of Bangladesh. Appl Geogr 24:217-240. https://doi.org/10.1016/j.apgeog.2004.03.004

Reddy CS, Pasha SV, Jha CS, Diwakar PG, Dadhwal VK (2016) Development of national database on long-term deforestation (1930-2014) in Bangladesh. Glob Planet Chang 139:173-182. https://doi.org/10.1016/j.gloplacha.2016.02.003

Robinson DT, Brown DG, French NH, Reed BC (2013) Linking land use and the carbon cycle. Land use and the carbon cycle: advances in integrated science, management, and policy. Cambridge University Press, Cambridge. https://doi.org/10.1017/CBO9780511894824.003
Santoro M, Kirches G, Wevers J, Boettcher M, Brockmann C, Lamarche C, Defourny P (2017) Land Cover CCI: Product User Guide Version 2.0. Available at https://maps.elie.ucl.ac.be/CCI/viewer/download/ ESACCI-LC-Ph2-PUGv2_2.0.pdf

Sbafizadeh-Moghadam H, Minaei M, Feng YJ, Pontiu RG (2019) GlobeLand30 maps show four times larger gross than net land change from 2000 to 2010 in Asia. Int J Appl Earth Obs Geoinf 78:240-248. https://doi.org/10.1016/j.jag.2019.01.003

Schmidt G, Jenkerson CB, Masek J, Vermote E, Gao F (2013) Landsat ecosystem disturbance adaptive processing system (LEDAPS) algorithm description. US Geological Survey, Reston. https://doi.org/10. 3133/ofr20131057

Shamsuzzaman MM, Islam MM, Tania NJ, Al-Mamun MA, Barman PP, Xu X (2017) Fisheries resources of Bangladesh: present status and future direction. Aquac Fish 2:145-156. https://doi.org/10.1016/j. aaf.2017.03.006

Sloan S (2015) The development-driven forest transition and its utility for REDD. Ecol Econ 116:1-11. https://doi.org/10.1016/j.ecolecon. 2015.04.010

Sloan S, Sayer JA (2015) Forest resources assessment of 2015 shows positive global trends but forest loss and degradation persist in poor tropical countries. For Ecol Manag 352:134-145. https://doi.org/10. 1016/j.foreco.2015.06.013

Soil Resource Development Institute (2013) Trends in the availability of agricultural land in Bangladesh

Song XP, Hansen MC, Stehman SV, Potapov PV, Tyukavina A, Vermote EF, Townshend JR (2018) Global land change from 1982 to 2016. Nature 560:639-643. https://doi.org/10.1038/s41586-018-0411-9

Thapa GB, Rasul G (2006) Implications of changing national policies on land use in the Chittagong Hill tracts of Bangladesh. J Environ Manag 81:441-453. https://doi.org/10.1016/j.jenvman.2005.12.002

U.S. Geological Survey (2001) Geologic and geophysical data of Bangladesh. Reston. https://doi.org/10.3133/ofr $97470 \mathrm{H}$

Uddin K, Shrestha HL, Murthy MS, Bajracharya B, Shrestha B, Gilani H, Pradhan S, Dangol B (2015) Development of 2010 national land cover database for the Nepal. J Environ Manag 148:82-90. https:// doi.org/10.1016/j.jenvman.2014.07.047

Xu XM, Du ZQ, Zhang H (2016) Integrating the system dynamic and cellular automata models to predict land use and land cover change. Int J Appl Earth Obs Geoinf 52:568-579. https://doi.org/10.1016/j.jag.2016.07. 022

Xu X, Jain AK, Calvin KV (2019) Quantifying the biophysical and socioeconomic drivers of changes in forest and agricultural land in south and Southeast Asia. Glob Chang Biol 25:2137-2151. https:// doi.org/10.1111/gcb.14611

Yang LP, Meng XM, Zhang XQ (2011) SRTM DEM and its application advances. Int J Remote Sens 32:3875-3896. https://doi.org/10. 1080/01431161003786016

Yesmin R, Mohiuddin ASM, Uddin MJ, Shahid MA (2014) Land use and land cover change detection at Mirzapur Union of Gazipur District of Bangladesh using remote sensing and GIS technology. Paper presented at the 7th IGRSM international remote sensing \& GIS conference and exhibition, Kuala Lumpur, Malaysia. https://doi. org/10.1088/1755-1315/20/1/012055

Zeng Z, Gower DB, Wood EF (2018a) Accelerating forest loss in southeast Asian massif in the 21st century: a case study in Nan Province, Thailand. Glob Chang Biol 24:4682-4695. https://doi.org/10.1111/gcb.14366

Zeng Z, Estes L, Ziegler AD, Chen A, Searchinger T, Hua F, Guan K, Jintrawet A, Wood EF (2018b) Highland cropland expansion and forest loss in Southeast Asia in the twenty-first century. Nat Geosci 11:556-562. https://doi.org/10.1038/s41561-018-0166-9

Publisher's note Springer Nature remains neutral with regard to jurisdictional claims in published maps and institutional affiliations. 